Article

\title{
Can Environmental Regulations Promote Corporate Environmental Responsibility? Evidence from the Moderated Mediating Effect Model and an Empirical Study in China
}

\author{
Benhong Peng ${ }^{1,2}$, Yu Tu ${ }^{1, *}$ and Guo Wei ${ }^{3}$ \\ 1 School of Management Science and Engineering, Nanjing University of Information Science \& Technology, \\ Nanjing 210044, China; 002426@nuist.edu.cn \\ 2 Institute of Climate Change and Public Policy, Nanjing University of Information Science \& Technology, \\ Nanjing 210044, China \\ 3 Department of Mathematics \& Computer Science, University of North Carolina at Pembroke, Pembroke, \\ NC 28372, USA; guo.wei@uncp.edu \\ * Correspondence: tuy@nuist.edu.cn
}

Received: 8 January 2018; Accepted: 23 February 2018; Published: 28 February 2018

\begin{abstract}
Based on the Stakeholder theory, a moderated mediating effect model is developed to reach the study objective, revealing an important connection that suggests environmental regulations (ERs) influence corporate environmental responsibility (CER) (Porter Hypothesis). In building the model, the validity of the questionnaire data was analyzed with factor analysis. By employing a two-step approach, a regression analysis is utilized to discuss the mediating effect of altruistic motivation and moderating effect of green innovation, and a structural equation model is used to explore the interactive mechanism of different variables. It is found that altruistic motivation plays a medium role in the relationship between ERs and CER, and green innovation engages a positive coordination in the relationship. The empirical study identifies factors affecting enterprises' willingness to undertake environmental responsibility, including environment policies, corporate culture, and personal characters among others. It is also revealed that altruistic motivation is conducive to forming a community interests among enterprises and enhancing their resistance to market risks, which explains and corroborates the Stakeholder theory; and the higher the level of green innovation, the more willing enterprises are to implement environmentally friendly operations.
\end{abstract}

Keywords: environmental regulation; corporate environmental responsibility; altruistic motivation; green innovation; Porter Hypothesis

\section{Introduction}

The Environmental Performance Index: 2016 Report indicated that Chinese environmental performance index (EPI) ranked 109 among 180 countries. Particularly, China is the hardest hit by PM2.5 haze disasters, which have posed a significant threat to physical health as well as living quality of all residents [1]. A recent study published in Nature estimated that outdoor air pollution, mostly by PM2.5, leads to 3.3 (95 percent confidence interval 1.61-4.81) million premature deaths per year worldwide, predominantly in Asia. Surprisingly, 1.357 million, or 41.2 percent of the world total, occurred in China alone [2]. To compare, the figure for the United States is 55,000. Along with a Lancet study [3], the mortality attributable to air pollution in China is approximately an order of magnitude higher than that attributable to Chinese road transport injuries and HIV/AIDS, and ranks among the top causes of death. Furthermore, according to Chinese Environmental Situation Communique in 2016 , only 84 cities and provinces could meet the air quality standard out of 338 cities and provinces 
$(24.9 \%)$ in China. Therefore, environmental conditions in China are becoming critically worse [4]. Consequently, national appeals about an ecological low-carbon environment have been spread all over the country [5], as Chinese citizens have raised awareness of environmental protection [6]. As such, environmental regulations (ERs) with external constraints eliminating or reducing various pollutions emerge and their role is widely concerned with raising the level of corporate environmental responsibility (CER) [7].

In this study, ERs refer to a series of mandatory requirements from administrative and public powers, emphasizing the coordination between environmental safety and economic benefits, and developing and utilizing resources by setting goals of harmonious development between the social-economic demands and environment [8]. Faced with intensifying environmental problems, governments at all levels must strengthen the implementation of ERs to promote related industries and enterprises to undertake environmental responsibilities and seek a synergetic growth of environment and economy [9]. Meanwhile scholars pay great attention to the effect of ERs from both the business growth and the level of environmental destruction $[10,11]$. There is a growing trend of research that investigates the positive and negative influences of ERs. Three representative opinions are formed, Traditional Hypothesis [12], Porter Hypothesis [13] and Uncertainty Hypothesis [14]. However, the existing research mainly focuses on the influence mechanism of ERs on business performance; fewer explore the internal reasons for interaction. Hence, exploring the interactive mechanism of ERs on the CER becomes a vital issue.

$\mathrm{Wu}$ et al. suggested that corporate culture and manager's personal features are among key factors that influence enterprise decisions [15]. Moreover, in research concerning CER, altruistic motivation and green innovation are respectively the most representative personal feature factor and corporate culture factor $[16,17]$. In addition, China is implementing a comprehensive extended producer responsibility (EPR) system, which is one of the most representative ERs [18]. Subsequently, studying CER while neglecting the influence of altruistic motivation or green innovation is likely to lead to a poor theoretical integrity or poor practical guidance in conclusions. Our main aim is to investigate the interactive mechanism of ER on CER, taking personal features (altruistic motivation) and corporate culture (green innovation) into account.

In the remainder of the paper, Section 2 presents an overview of related literature and formulates research hypotheses. Section 3 describes the methodology and deals with the pre-test of research hypotheses. In Section 4, we elaborate the empirical results. Section 5 discusses the results obtained. Section 6 provides conclusions and significance in our research. Finally, Section 7 outlines the limitations of the study and ensuing future perspectives of research.

\section{Conceptual Framework and Research Hypothesis}

\subsection{Theoretical Review}

Environmental pollution and ecological damage have reached an unprecedented situation in China [19]. As the primary resource consumers, enterprises have inescapable responsibilities for environmental problems. However, Friedman pointed out that an enterprise is a profitable organization and has a typical feature of profit-seeking: aiming at to increase the operating efficiency and economic benefits, enterprises will choose to abandon environmental responsibilities gradually [20]. Moreover, they tend to intensify environmental pollution once ERs cannot prevent their sabotages. Thus, it is easy to see that ER is faced with substantial challenges all over the world [21]. Meanwhile, based on the Stakeholder theory, Lee reported that corporate social responsibility strategies are influenced by public opinions including the media, except for institutional factors such as ERs [22].

As the leading regulation role of the market mechanism is determined in China [23], ERs influence CER through multiple forms such as environmental taxes, administrative fines, a cap-and-trade system, production subsidies and special trading. In particular, the internal function routes need further discussions to provide practice implications. Hambrick and Mason point out that corporate 
decisions reflect psychological features of a management layer [24]. If a general manager has a strong sense of environmental protection, he or she would not blindly chase high profits at the expense of environmental damage. Haniffa and Hudaib also believe that responsible behaviors are consistent with the cognition of managers in enterprises [25]. Therefore, as a representative personal feature [26], altruistic motivation might play an important role in the action process of ERs on CER. Meanwhile, enterprise values, which are an important influencing factor in decision-making, also have non-negligible impact on CER [27]. Both academia and business circles generally deem green innovation to be a value manifestation that enterprises use to cope with ERs and improve competitive advantages [28]. Paying attention to the moderating effect of green innovation on the relationship between ER and CER is conducive to clearly showing their conditional and indirect relationship.

\subsection{ER and CER}

In 1998, McGee first discussed the reasons why enterprises had to undertake environmental responsibilities [29], and institution, morality and the economy are widely accepted as three main reasons [30]. However, along with deepening social divisions of labor and the great extension of industrial chains around the world, the phenomenon of information inaccuracy is becoming more and more serious. The matching of supply and demand is getting remarkably difficult in the market [31]. In other words, low efficiency of the market mechanism in resource allocation tends to be a prominent problem. ERs, which are regarded as "tangible hands", have become an important reason for enterprises to fulfill environmental responsibilities [32]. Effects of ERs are mainly manifested by policy constraint and public opinion.

The government guides enterprises to adopt environmental protection behaviors by formulating specific and detailed policies. Enterprises must improve production modes for institutional pressure. For instance, to avoid a fine or stopping business for internal rectification, they will implement ecological design and waste preprocessing, develop environmentally friendly products, and make legal production activities [33]. In contrast, based on the comparison of disclosure of corporate environmental information in China and Japan, He found that with the increase of environmental awareness among the public, public opinions are more likely to pay close attention to environmental information disclosure in enterprises, except for policy constraints [34]. Enterprises must undertake environmental responsibilities and adopt green production to meet green consumption demands which are popular in the modern consumer market. Thus, the first hypothesis is proposed:

\section{Hypothesis 1 (H1). ERs have positive correlation with CER.}

\subsection{Mediating Effect of Altruistic Motivation}

China's economic development has entered a new era. Meanwhile, consumption upgrading is accelerating remarkably in China [35]. Goods labelled with green signs can always cater to consumer demand and sell well. On the other hand, enterprises adopting environmentally-friendly technologies in production also get more advantages in marketing competition. Because they meet consumers' needs of environmental protection [36], enterprises are motivated to undertake responsibilities for environmental protection.

Orlitzky et al. doubted a previous conclusion that enterprises undertake social responsibilities for financial motivation [37]. Graafland explained the causes of altruistic motivation from perspectives of external pressure and self-knowledge [38]. On the one hand, government, consumers, and stakeholders require enterprise managers to take all involved parties into consideration all the time. This compels managers to accept altruistic motivation passively. On the other hand, huge pressure from stakeholders forces enterprise managers to accept altruistic motivation subjectively because passive behaviors such as evading supervision will lead to an increase in the cost of business operations. Moreover, the punishment will be severe once passive behaviors come to light [39]. In addition, with the development of networked social structures, Osman believed that the 
traditional competitive relationships among enterprises would be gradually replaced by the friendly co-petition relationship [40]. If enterprise managers can pursue interests of all stakeholders rather than maximization of their own economic benefits, they will view environmental protection as a moral responsibility that they must do [41]. Besides, enterprises will also gain legal, market and psychological recognition from environmental protection behaviors. Therefore, managers who work as the direct makers of business strategies, through their personal features-altruistic motivation-will influence an enterprise's willingness to undertake environmental responsibilities directly, and the effect of ERs on CER is to adopt the altruistic motivation as a mediator variable. Thus, the second hypothesis is proposed:

Hypothesis 2 (H2). Altruistic motivation can mediate the relationship between ERs and CER.

\subsection{Moderating Effect of Green Innovation}

ERs and manager's personal features will influence business decisions. However, corporate culture determines the extent of influence [42]. In other words, the corporate culture regulates the effects of other factors on business decisions. Chen et al. pointed out that the green innovation is the key corporate cultural factor nowadays [43]. It has become a powerful tool for enterprises to improve competitive advantages [36]. If green innovation could be internalized into initiative behaviors in an enterprise's daily operation, the consciousness of environmental protection would be profoundly embedded into the corporate culture. When faced with selection between economic benefits and environmental interests, green innovation will encourage enterprises to undertake environmental responsibilities positively [44]. Much research has divided green innovation into green products and green technique [45]; however, both forms of green innovation must be integrated into the entire life cycle of products. This will help realize differentiation advantages of products and gain approvals from both the policy and the market. Nevertheless, business decisions are faced with far higher uncertainty and complexity compared with individual decisions, especially under the background of the relatively light penalty for environmental pollution in China. As a result, most enterprises have not undertaken their environmental responsibilities and they usually implement green innovation selectively as a result of fluke mind or high cost [46]. Therefore, green innovation has no constraint on CER, but only regulates the influence. Thus, the third hypothesis is proposed:

Hypothesis 3 (H3). Green innovation can regulate the relationship between ERs and CER.

\subsection{Moderated Mediating Effect}

The mediating effect of altruistic motivation and moderating effect of green innovation have been discussed previously in this section. Referring to Edwards and Lambert, who put forward a moderated mediating effect model [47], we hold the view that green innovation also regulates the mediating effect of altruistic motivation on the relationship between ERs and CER. Once enterprises integrate green innovation into daily business operations, perceptual factors like altruistic motivation will impel enterprises to undertake environmental responsibility actively. Accordingly, the indirect effect of ERs on CER will be enhanced. Thus, the fourth hypothesis is proposed:

Hypothesis 4 (H4). Green innovation can regulate the mediating effect of altruistic motivation on the relationship between ERs and CER.

Figure 1 displays the theoretical framework of the moderated mediating effect model. 


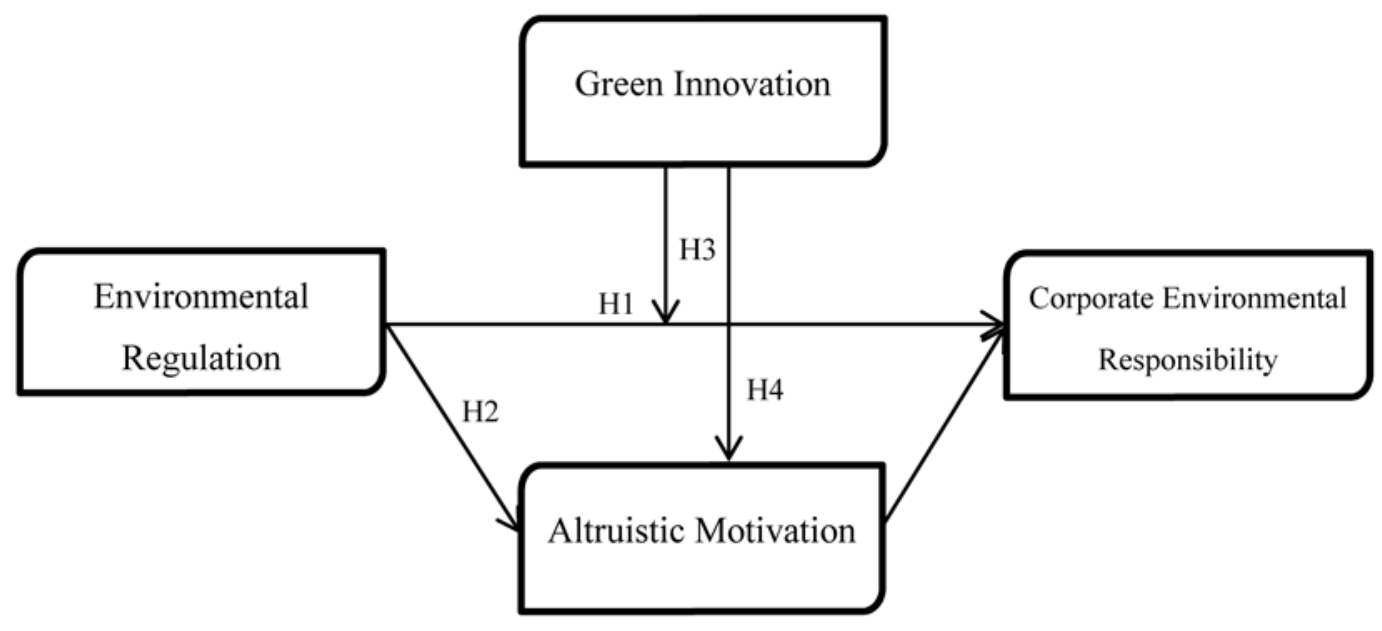

Figure 1. Conceptual framework.

\section{Methodology}

\subsection{Questionnaire Design and Data Collection}

In this study, a 7-mark Likert scale where "1" represents strong disagreement and "7" represents strong agreement was used. Empirical data were collected by questionnaire survey. China published the Plan of Extended Producer Responsibility System in January 2017. It stipulates that manufacturing enterprises are assigned to high-pollution enterprises, including electric and electronic enterprises. Meanwhile, scholars generally believe that manufacturing enterprises are the main cause of environmental pollution [47]. Therefore, we mainly chose manufacturing enterprises as research objects. Enterprise samples include electric and electronic manufacturing enterprises, automobile manufacturing enterprises and lead-acid battery production enterprises. Additionally, to ensure representativeness of questionnaire data, enterprise samples were widely located in the Yangtze River Delta region, Pearl River Delta region, northeast industrial zone, and middle and west regions in China. Questionnaires were issued in paper form or by e-mail. Respondents were all informed about the academic purpose and specific filling requirements before filling out the questionnaire. All questionnaires were completed anonymously to assure the safety of respondent's personal information.

To guarantee validity of survey data and reduce effects of random factors on conclusions, questionnaires were issued and collected from February to May 2017. A total of 300 questionnaires were distributed and 239 were collected. After processing and screening, 218 effective questionnaires were utilized, showing an effective rate of $72.6 \%$. Statistical information about key features of valid questionnaires is shown in Table 1. Ownership types of enterprise samples include state-owned or state holding enterprises, private enterprises, and foreign-owned enterprises or Sino-foreign joint ventures. Enterprise scales cover the mini (less than 100 workers), small-sized (from 100 to 300 workers), mid-sized (from 300 to 600 workers) and large-sized (more than 600 workers). Among them, $81.7 \%$ of enterprises have an annual sale volume of over RMB 100 million, which ensures representativeness of questionnaire data. Respondents include CEOs, general managers, directors of production and marketing departments, professional technicians, and researchers, which helps avoid sample deviation. Viewed by working years in related industries, $63.7 \%$ of respondents have more than 3 working year is in industry. This ensures the reliability of survey data. 
Table 1. Statistical information about key features of valid samples.

\begin{tabular}{clcc}
\hline \multirow{2}{*}{ Category } & \multicolumn{1}{c}{ Distribution } & Sample Size & Percentage (\%) \\
\hline \multirow{5}{*}{ Ownership nature } & State-owned or state-controlled enterprise & 58 & 26.6 \\
& Private enterprise & 109 & 50.0 \\
& Foreign-capital enterprise & 21 & 9.6 \\
& Joint-venture enterprise & 30 & 13.8 \\
\hline \multirow{5}{*}{ Enterprise scale } & Less than 100 workers & 16 & 7.3 \\
& From 100 to 300 workers & 31 & 14.2 \\
& From 300 to 600 workers & 69 & 31.7 \\
& More than 600 workers & 102 & 46.8 \\
\hline \multirow{5}{*}{ Annual turnover } & Less than 60 million yuan & 5.5 \\
& From 60 million to 100 million yuan & 12 & 12.8 \\
& From 100 million to 300 million yuan & 28 & 39.5 \\
& More than 300 million yuan & 86 & 42.2 \\
\hline \multirow{5}{*}{ Position } & Top-level manager & 92 & 33.0 \\
& Department head & 72 & 39.5 \\
& Technician & 86 & 7.3 \\
& Scientific personnel & 16 & 20.2 \\
\hline \multirow{5}{*}{ Industry } & Less than 1 year & 44 & 6.9 \\
& From 1 to 3 years & 15 & 29.4 \\
& From 3 to 5 years & 64 & 37.1 \\
& More than 5 years & 81 & 26.6 \\
\hline \multirow{2}{*}{ Operating age } & Electrical and electronic & 58 & 39.9 \\
& Automobile & 83 & 28.8 \\
& Lead-acid battery & 60 & 31.3 \\
\hline & & 65 & \\
\hline
\end{tabular}

\subsection{Variable Measurement}

This survey was divided into a pre-survey and a formal survey. The pre-survey was accomplished in Nanjing development zone and chemical park. Five junior or senior managers working in petroleum, chemical engineering and machinery companies were invited to a semi-structured interview (including two general managers in state-owned enterprises, one head of security services in a state state-controlled enterprise, one director of environmental affairs in a listed company and one general manager in a private enterprise). Next, questions in the scale were translated into Chinese and English by the double-blind method with references to mature scales at home and abroad. After careful discussions and amendments, the final formal questionnaire contents were determined by the third party. During formal survey, to reduce self-selection deviations and eliminate disturbances of social desirability, the non-commercial purpose of our study was declared again in the filling instructions. Meanwhile, real contact information of respondents was provided by human resource department in the enterprise, and target respondents were mainly those who have worked in high-pollution industries for many years. All above were aimed at increasing the quality of questionnaire data.

Measurement scale includes: (1) ER. According to Kshetri [48] and Feng [49], three items were designed to measure the regulations implemented by government departments. With references to research conclusions from Tian and Liu [50], four items about clients, community and media were designed to measure the regulations implemented by public opinion; (2) CER. It was divided into corporate community responsibility and corporate environmental responsibility according to the research scale used by Wahba [51] and Testa and D'Amato [52]. It was measured by five items, such as "We help to increase living quality of community actively"; (3) Altruistic motivation. According to the altruistic motivation evaluation system proposed by Schwartz and Boehnke from the perspectives of humanity, tradition, and safety [53], six items were set with consideration to the particular Chinese situation; (4) Green innovation. Combining with research obtained by Chang [54], it was measured from two aspects of green product innovation and green technology innovation. 
Noteworthy, key features of samples will influence CER significantly [55], and hence we chose the size of an enterprise and the nature of the ownership as the control variables. The former was measured by employee population at four levels: 1 (less than 100 workers); 2 (from 100 to 300 workers); 3 (from 300 to 600 workers) and 4 (more than 600 workers). The latter was further divided into two categories: " 1 " stands for state-owned or state-controlled enterprises, and " 0 " stands for non-state-owned enterprises. These two control variables will be transformed into dummy variables before hypotheses are verified.

\subsection{Reliability and Validity Measurement}

The reliability of the 218 questionnaire data was validated by SPSS18.0. The overall reliability index of Cronbach's $\alpha$ is 0.725 ( $>0.7)$, which reflects a good internal consistence of our questionnaire contents. As shown in Table 2, Cronbach's $\alpha$ values of all variables are higher than $0.7, \mathrm{KMO}$ values are all higher than 0.6 , and $\mathrm{F}$ values of Bartlett's test are all 0 . The minimum value of factor explainable variance is $63.706 \%$. All these indicate that our scale is quite stable and has a high reliability.

Table 2. Measurement validation.

\begin{tabular}{ccccc}
\hline Variable & Cronbach's $\boldsymbol{\alpha}$ & KMO Value & F Value of Bartlett's Test & Percent Explained (\%) \\
\hline ER & 0.714 & 0.658 & 0.000 & 63.706 \\
CER & 0.738 & 0.686 & 0.000 & 65.619 \\
Altruistic motivation & 0.822 & 0.677 & 0.000 & 74.805 \\
Green innovation & 0.869 & 0.732 & 0.000 & 62.738 \\
\hline
\end{tabular}

Furthermore, the validity of items is analyzed by AMOS17.0. Results demonstrate that $\chi^{2} / \mathrm{df}=2.208(<3), \mathrm{NFI}=0.937(>0.9), \mathrm{CFI}=0.964(>0.95), \mathrm{RMSEA}=0.037(<0.05)$ and SRMR $=0.050(<0.1)$. These indicate a goodness of fit and our hypothetical model conforms to research requirements. In addition, as shown in Table 3, the composite reliability of items is higher than 0.7 and all factor loadings are higher than 0.5. Most of the factor loadings are higher than 0.6 , and mainly at about 0.7. Individual values are also higher than the minimum standard of 0.5 . This reflects a high convergent validity of the questionnaire. Finally, all variables' square root of average variance extracted values (AVE) are higher than the correlation coefficient between the variable and other variables, which also shows a good discriminant validity.

Table 3. Confirmatory factor analysis.

\begin{tabular}{|c|c|c|c|c|}
\hline Variable & Item & Factor Loading & $\begin{array}{l}\text { Composite } \\
\text { Reliability }\end{array}$ & AVE \\
\hline \multirow{5}{*}{ ER } & Environmental policies are systematic and specific. & 0.559 & \multirow{5}{*}{0.750} & \multirow{5}{*}{0.435} \\
\hline & Existing punishments in ERs are severe. & 0.612 & & \\
\hline & Business operations are in the supervision from the public and the media. & 0.694 & & \\
\hline & $\begin{array}{l}\text { Journalists focus on negative reports about enterprise operations such as } \\
\text { pollution discharge surreptitiously. }\end{array}$ & 0.549 & & \\
\hline & $\begin{array}{l}\text { The public prefers goods produced with } \\
\text { environmentally-friendly technologies. }\end{array}$ & 0.727 & & \\
\hline \multirow{3}{*}{ CER } & $\begin{array}{l}\text { We take environmental protection into consideration when formulate } \\
\text { strategies for business. }\end{array}$ & 0.694 & \multirow{3}{*}{0.712} & \multirow{3}{*}{0.450} \\
\hline & We help to increase living quality of community actively. & 0.681 & & \\
\hline & Our social reputations are elevated due to green management. & 0.630 & & \\
\hline
\end{tabular}


Table 3. Cont.

\begin{tabular}{|c|c|c|c|c|}
\hline Variable & Item & Factor Loading & $\begin{array}{l}\text { Composite } \\
\text { Reliability }\end{array}$ & AVE \\
\hline \multirow{4}{*}{$\begin{array}{c}\text { Altruistic } \\
\text { motivation }\end{array}$} & We share the environment. & 0.785 & \multirow{4}{*}{0.733} & \multirow{4}{*}{0.486} \\
\hline & Our environmentally-friendly practices would affect others positively. & 0.621 & & \\
\hline & We response to the call for ecological civilization construction in China. & 0.664 & & \\
\hline & Later generations would benefit from green production technologies. & 0.637 & & \\
\hline \multirow{3}{*}{$\begin{array}{c}\text { Green } \\
\text { innovation }\end{array}$} & $\begin{array}{l}\text { The concept of environmental protection is integrated into the product } \\
\text { design and packaging. }\end{array}$ & 0.723 & \multirow{3}{*}{0.791} & \multirow{3}{*}{0.550} \\
\hline & Outlook on green development has incorporated into production process. & 0.742 & & \\
\hline & Production technologies need to be environmentally-friendly. & 0.711 & & \\
\hline
\end{tabular}

\subsection{Descriptive Statistics}

Mean, variance and Pearson correlation coefficient are shown in Table 4. Results show that ER has positive impacts on CER $(\beta=0.134, p<0.05)$. Altruistic motivation is positively correlated with CER ( $\beta=0.256, p<0.01)$. The green innovation has a positive correlation with $\operatorname{ER}(\beta=0.115, p<0.05)$ and CER $(\beta=0.185, p<0.05)$. According to the analysis, correlation coefficients of variables are consistent with previous hypotheses and conform to the theoretical expectation.

Table 4. Mean, standard deviation and correlation coefficient of variables.

\begin{tabular}{ccccccccc}
\hline Item Variable & Mean & Standard Deviation & $\mathbf{1}$ & $\mathbf{2}$ & $\mathbf{3}$ & $\mathbf{4}$ & $\mathbf{5}$ \\
\hline Enterprise scale & 5.816 & 0.644 & 1 & & & & \\
Ownership nature & 2.374 & 1.215 & -0.001 & 1 & & \\
ER & 3.135 & 0.640 & $0.251^{*}$ & 0.175 & 1 & & \\
CER & 4.239 & 0.518 & 0.044 & $0.239 *$ & $0.134^{*}$ & 1 & \\
Altruistic motivation & 3.718 & 0.689 & 0.087 & 0.062 & 0.286 & $0.256^{* *}$ & 1 \\
Green innovation & 3.461 & 0.903 & 0.046 & $0.156^{*}$ & $0.115^{*}$ & $0.185^{* *}$ & $0.206^{* *}$ & 1 \\
\hline
\end{tabular}

Note: ${ }^{*}$ and ${ }^{* *}$ represent the level of significance of coefficients at $p<0.05$ and $p<0.01$ respectively.

\section{Hypothesis Testing}

\subsection{Regression Analysis}

Hypothesis $\mathrm{H} 2$ is to test the mediating effect of altruistic motivation in the relationship between ERs and CER. Based on sequential regression analysis (Baron and Kenny) [56], the mediating effect of altruistic motivation is studied in four steps: 1) regression analysis of independent variable on dependent variable; (2) Regression analysis of independent variable on mediator variable; (3) Regression analysis of mediator variable on dependent variable; (4) Regression analysis of independent variable and mediator variable on dependent variable (in this step, coefficient of independent variable should be lower than that in step 1). It can be seen from Table 5 that ER has a positive impact on CER $(\beta=0.341, p<0.01)$. ER has a positive impact on altruistic motivation $(\beta=0.236, p<0.05)$. In addition, altruistic motivation has a positive impact on CER $(\beta=0.187, p<0.05)$. While ER $(\beta=0.309, p<0.05)$ and altruistic motivation $(\beta=0.096, p<0.05)$ also have a positive impact on CER, the positive impact of ER decreases $(0.341>0.309)$. To sum up, ER has a significantly positive impact on CER. So, hypothesis H1 is proved true. At the same time, altruistic motivation works as a mediator variable in the relationship between ERs and CER, so hypothesis H2 is proved true. In Table 5, coefficients in parentheses are calculated through Ordered Probit Model. It is discovered that most of these coefficients are consistent with those from sequential regression analysis, including positive and negative and the level of significance. This further verifies the results of sequential regression analysis. 
Table 5. Results of regression analysis.

\begin{tabular}{|c|c|c|c|c|c|c|}
\hline \multirow{2}{*}{ Independent Variable } & \multirow{2}{*}{$\begin{array}{c}\text { Altruistic Motivation } \\
\text { Model } 1\end{array}$} & \multicolumn{5}{|c|}{ CER } \\
\hline & & Model 2 & Model 3 & Model 4 & Model 5 & Model 6 \\
\hline Enterprise scale & $\begin{array}{c}0.014 \\
(0.008)\end{array}$ & $\begin{array}{c}0.135^{* *} \\
\left(0.074^{* *}\right)\end{array}$ & $\begin{array}{c}0.156^{*} \\
\left(0.087^{* *}\right)\end{array}$ & $\begin{array}{c}0.205^{* *} \\
\left(0.113^{* *}\right)\end{array}$ & $\begin{array}{l}0.079 * \\
(0.044)\end{array}$ & $\begin{array}{l}0.075 * \\
(0.041)\end{array}$ \\
\hline Ownership nature & $\begin{array}{c}0.006 \\
(0.003) \\
\end{array}$ & $\begin{array}{c}0.243^{* *} \\
\left(0.134^{* *}\right)\end{array}$ & $\begin{array}{c}0.097 \\
(0.054) \\
\end{array}$ & $\begin{array}{c}0.153 * \\
(0.085 *) \\
\end{array}$ & $\begin{array}{c}0.136^{*} \\
\left(0.075^{*}\right) \\
\end{array}$ & $\begin{array}{l}0.128 * \\
(0.070 *)\end{array}$ \\
\hline ER & $\begin{array}{c}0.236^{*} \\
\left(0.130^{* *}\right)\end{array}$ & $\begin{array}{c}0.341^{* *} \\
\left(0.188^{* *}\right)\end{array}$ & & $\begin{array}{c}0.309^{*} \\
\left(0.170^{* *}\right)\end{array}$ & & \\
\hline Altruistic motivation & & & $\begin{array}{c}0.187^{*} \\
(0.103 *)\end{array}$ & $\begin{array}{c}0.096 * \\
(0.053 *)\end{array}$ & & \\
\hline Green innovation & & & & & $\begin{array}{l}0.438^{* *} \\
\left(0.243^{* *}\right)\end{array}$ & \\
\hline ER $\times$ Green innovation & & & & & & $\begin{array}{c}0.414^{*} \\
\left(0.229^{* *}\right)\end{array}$ \\
\hline $\mathrm{R}^{2}$ & 0.416 & 0.510 & 0.457 & 0.590 & 0.604 & 0.623 \\
\hline F value & $6.042 *$ & $43.409^{* *}$ & $21.372 *$ & $34.861 *$ & $64.887^{* *}$ & $65.364 *$ \\
\hline D-Watson & 1.973 & 2.127 & 2.214 & 2.252 & 2.075 & 2.094 \\
\hline
\end{tabular}

Note: ${ }^{*}$ and ${ }^{* *}$ represent the level of significance of coefficients at $p<0.05$ and $p<0.01$ respectively.

Hypothesis $\mathrm{H} 3$ is to verify the moderating effect of green innovation in the relationship between ERs and CER. In Table 5, the interaction term of ER and green innovation has a positive influence on CER $(\beta=0.414, p<0.05)$. In addition, the explanation of interaction term is $2 \%$ higher than that of green innovation alone. We choose one positive or negative standard deviation of mean to disclose the moderating effect of green innovation in the relationship more clearly. As shown in Figure 2, green innovation can regulate the relationship between ERs and CER. Hypothesis H3 is proved true.

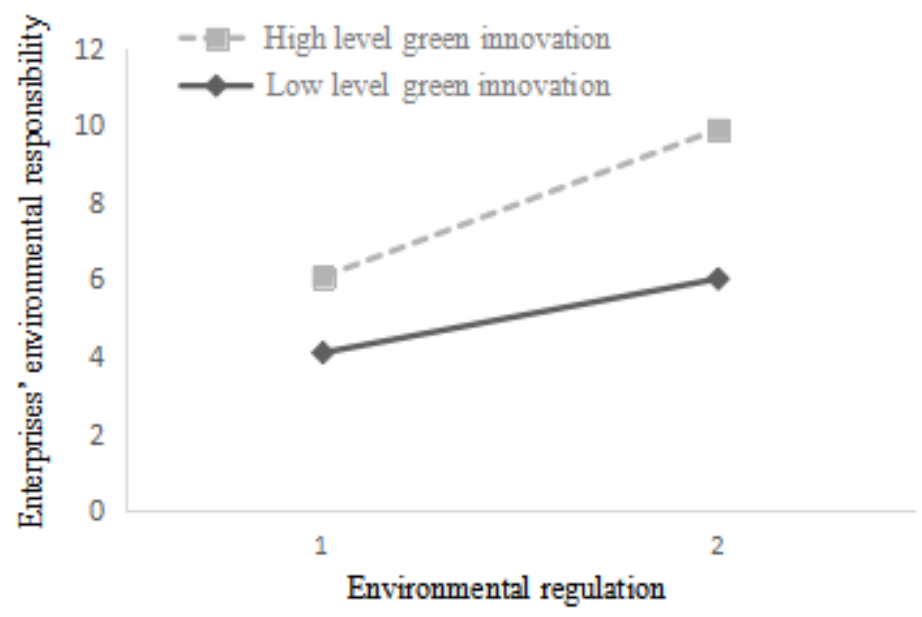

Figure 2. Moderating effect of green innovation.

Hypothesis $\mathrm{H} 4$ is proposed to verify whether green innovation could regulate the mediating effect of altruistic innovation. According to Moderated Path Analysis [47], calibrated confidence interval of 1000 samples is gained by Bootstrap method, which can analyze the mediating effect and the significance test of difference. To display results of moderated mediating effect model intuitively, two equations are constructed in our study: (1) $M=\beta 1+\beta 2 X$ and (2) $\mathrm{Y}=\alpha 1+\alpha 2 \mathrm{X}+\alpha 3 \mathrm{M}+\alpha 4 \mathrm{Z}+\alpha 5 \mathrm{M} \times \mathrm{Z}$, where $\mathrm{X}, \mathrm{Y}, \mathrm{M}$ and $\mathrm{Z}$ represent respectively independent variable (ER), dependent variable (CER), mediator variable (altruistic motivation) and moderator variable (green innovation). In addition, Equation (1) is utilized to display the first-stage impact of moderated mediating effect model, while Equation (2) is used to reflect the second-stage impact and direct impact. Table 6 shows that ER under high-level green innovation influences the mediating effect 
of altruistic motivation more strongly compared to that under low-level green innovation. In addition, the intergroup difference in the second stage is 0.117 and conforms to the requirement of significance. In addition, whether green innovation is low level $(\beta=0.057, p<0.01)$ or high level $(\beta=0.144, p<0.05)$, the indirect effects are both significant. Here, the intergroup difference is 0.087 , which also passes the test of significance $(p<0.01)$. To sum up, green innovation regulates the mediating effect of altruistic motivation. Therefore, hypothesis $\mathrm{H} 4$ is proved true.

Table 6. Moderated mediating effect model.

\begin{tabular}{cccccc}
\hline \multirow{2}{*}{ Moderator Variable } & \multicolumn{2}{c}{ Stage } & \multicolumn{3}{c}{ Effect } \\
\cline { 2 - 5 } & Stage One & Stage Two & Direct Effect & Indirect Effect & Cumulative Effects \\
\cline { 2 - 5 } & \multicolumn{4}{c}{ ER(X) $\rightarrow$ Altruistic Motivation(M) $\rightarrow$ CER(Y) } \\
\hline $\begin{array}{c}\text { Low-level green } \\
\text { innovation }\end{array}$ & $0.183^{* *}$ & $0.279^{* *}$ & $0.154^{* *}$ & $0.057^{* *}$ & $0.211^{* *}$ \\
$\begin{array}{c}\text { High-level green } \\
\text { innovation }\end{array}$ & $0.183^{* *}$ & $0.396^{* *}$ & $0.154^{* *}$ & $0.144^{* *}$ & $0.298^{* *}$ \\
Intergroup difference & & $0.117^{* *}$ & & $0.087^{* *}$ & $0.087^{* *}$ \\
\hline
\end{tabular}

Note: ${ }^{*}$ and ${ }^{* *}$ represent the level of significance of coefficients at $p<0.05$ and $p<0.01$ respectively.

\subsection{Structural Equation Model}

To reveal interactive relations of different variables, path fitting in research hypotheses is explored by structural equation model. In the aspect of fitting indexes, $\chi^{2} / \mathrm{df}=1.348(<3), \mathrm{CFI}=0.924(>0.7)$, AGFI $=0.907(>0.9), \mathrm{CFI}=0.885(<0.7)$ and RMESA $=0.040(<0.1)$. All indexes reach the acceptable standards, indicating the higher goodness of fit in our model.

Function route and path coefficient of structural equation model are listed in Table 7. Specifically, the path coefficient of ER on CER is 0.28 and passes the test of significance $(p<0.01)$. It shows that ER has a positive impact on CER. In other words, strict ERs will compel enterprises to take the initiative to undertake responsibilities for environmental protection. So, hypothesis $\mathrm{H} 1$ is supported. At the same time, the path coefficient of ER on altruistic motivation and that of altruistic motivation on CER are respectively $0.17(p<0.05)$ and $0.20(p<0.01)$. It demonstrates that positive effects of ER on altruistic motivation as well as the positive effects of altruistic motivation on CER. In addition, the altruistic motivation plays a mediator role on the relationship between ERs and CER. Therefore, hypothesis $\mathrm{H} 2$ is supported. The path coefficients of green innovation on ER, altruistic motivation and CER are respectively $0.14,0.27$ and 0.33 . All $\mathrm{P}$ values are smaller than 0.01 and the levels of significance meet related requirements. It indicates that the green innovation can positively regulate the effects of ER on CER. In other words, the higher the level of green innovation, the stronger the effects of ER on CER. So, hypothesis $\mathrm{H} 3$ is supported. To sum up, the results of structural equation model are consistent with that of regression analysis and this explains the mediating effect of altruistic motivation in detail, which further verifies the hypotheses.

Table 7. Results of structural equation model and corresponding hypotheses.

\begin{tabular}{ccccc}
\hline Function Route & Path Coefficient & F Value & Corresponding Hypothesis & Result \\
\hline ER $\rightarrow$ CER & 0.28 & $* *$ & H1 & Support \\
ER $\rightarrow$ Altruistic motivation & 0.17 & $*$ & H2 & Support \\
Altruistic motivation $\rightarrow$ CER & 0.20 & $* *$ & H2 & Support \\
Green innovation $\rightarrow$ ER & 0.14 & $* *$ & Support \\
Green innovation $\rightarrow$ Altruistic motivation & 0.27 & $* *$ & H3 & Reject \\
Green innovation $\rightarrow$ CER & 0.33 & $* *$ & Support \\
\hline Note: ${ }^{*}$ and ${ }^{* *}$ represent the level of significance of coefficients at $p<0.05$ and $p<0.01$ respectively.
\end{tabular}




\section{Discussion}

Based on the results of regression analysis and structural equation model, our research on the relationship between ERs and CER, which takes altruistic motivation as a mediator variable and green innovation as a moderator variable, has the following conclusions:

(1) Positive effects of ER on CER. Corporate initiative in shouldering environmental responsibility needs obligation by ERs and guidance by altruistic motivation (As shown in Model 2 and Model 3, Table 5, the coefficients both pass the significance test). This is different from previous conclusions that enterprises make environmental protection behaviors by a single factor [57]. Therefore, business managers should consider mandatory pressure of policies and non-mandatory influence of public opinion as well as overall interests of all stakeholders including supplier, client, and wholesaler. Then by undertaking environmental responsibility, enterprises can solve appeals of stakeholders and gain both social performance and competitive advantages [58]. Moreover, the empirical study above reveals that the correlation coefficient of ER on CER is positive (In Table 5, the coefficient is 0.341 . In Table 7 , the coefficient is 0.28 . In addition, they all pass the test of significance in $1 \%$ level). In other words, ER has a positive impact on CER, which verifies the Porter Hypothesis to the particular Chinese situation. In detail, ERs impose great pressure on enterprises which adopt old-fashioned production technologies. So those enterprises are forced to invest in pollution control technology and advanced production technology and implement environmentally friendly operations in the whole life cycle. Although enterprises must put abundant resources in the process of undertaking environmental responsibility, advantages (such as environmental tax refunding, productivity growth and social image improvement) which are brought from behaviors of environmental protection will contribute to long-term development [59]. So, if only enterprises focused on long-term development, they would have the initiative to implement environmental protection behaviors. In addition, it is the objective of ERs. Conversely, once more enterprises undertake environmental responsibility actively or more environmental responsibilities are accepted by enterprises on their own initiative, CER will be blended into an enterprise's daily operation and even into industry regulations [60]. Then corresponding ERs will be improved and enhanced. Therefore, the relationship between ERs and CER may be interacted.

(2) Mediating effect of altruistic motivation. In Figure 3, we can clearly find that altruistic motivation works as a mediator variable in the relationship between ERs and CER. So, value factors such as altruistic motivation play an important role in promoting enterprises to fulfill environmental protection responsibility. This disagrees with conclusions of Broon and Kenny [56]: policy constraint plays the decisive role in driving enterprises to adopt environmental protection technology [12]. However, a great change has taken place in the modern market. Unlike the concept of marketing in the late 1980s when Broon and Kenny were working, the concept of social marketing becomes more and more recognized this century, especially in the Internet era [61]. Faced with intensifying market competition and social networking, an enterprise's survival is determined not only by its strength, but also by the comprehensive interests of stakeholders including employees, clients, and social organizations [22]. Besides, alliance of government, production, teaching, research, and consumers contributes to information sharing and becomes an important way to improve an enterprise's discourse power in the industrial chain. It is becoming a popular pattern in modern business. So nowadays market competition has been evolved from the primary stage (individual-to-individual pattern) to the senior stage (group-to-group pattern) [62]. Therefore, business managers must set up the idea of altruism and integrate altruistic motivation into corporate culture. Furthermore, enterprises are supposed to formulate an operation strategy of "value co-production and win-win cooperation" and construct a platform for regular communication among partners, which can promote the free circulation of talents, information, technology, and other resources [63]. A community of shared interests 
thereby will be established. Altruistic behaviors are also necessary because the enhancement of ERs and CER is keeping up the pressure against the enterprises. Enterprise's competitive advantages will disappear gradually in the inter-group competition situation. The value of altruism is becoming an essential concept of operation in the Internet age.

(3) Moderating effect of green innovation. Regression analysis results reveal that green innovation can regulate the effects of ER on CER (s shown in Table 5, the coefficient of ER is 0.341 in Model 2, while the coefficient of interaction term, ER $\times$ Green innovation, is 0.414 in Model 6), and enterprises with high-level green innovation will implement environmental protection behaviors more actively (As shown Figure 2). So green innovation decides whether the enterprise could take an advantage in a fierce market competition. Enterprises with low-level green innovation should regard environmental protection as a profitable opportunity and implement a proactive environmental strategy [64]. This will help the enhancement of ERs and CER. Then mandatory constraint such as ERs, and non-mandatory factors such as CER and altruistic motivation, both will promote green innovation to get into business operation. Finally, green innovation will help enterprises take an unshakable advantage in reducing unnecessary costs such as avoiding supervision of environmental authorities and the public. Those enterprises also should actively improve environmental management level and realize a "win-win" between environmental performance and economic performance by setting about to construct a pollution-free and low-consumption production system from multiple aspects including product design, environmental governance, energy saving, emission reduction, pollution control as well as waste recycling. Subsequently, managers could improve the consciousness of green innovation by training or learning. Managers also need to enhance the propagation of environmental business culture to lead employees to accept and support green innovations [65]. It will help create a feasible atmosphere for green innovation. Meanwhile, the government must strengthen ERs and use different combinations of ERs such as command-control ER, market-based incentive ER and voluntary ER. The intensive cleaner production also needs to be introduced in laws to gradually dissolve the ecological crisis [66]. Not to be neglected, the media and the public should take their wider regulatory role in encouraging and supervising green innovation behaviors in enterprises. The media can expose an enterprise's production process in time and rev up publicity for green innovation. The public can choose green and environmentally friendly commodities or services proactively.

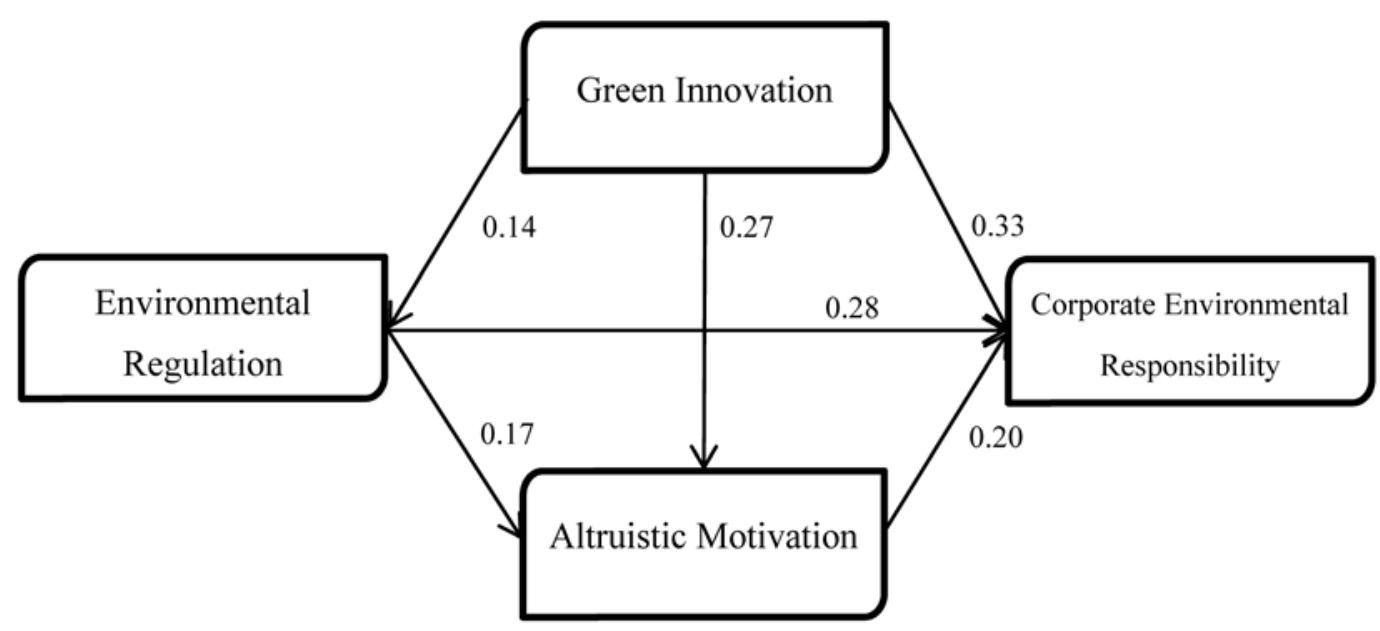

Figure 3. Results of structural equation model. 


\section{Conclusions}

An empirical study is carried out by using regression analysis and the structural equation model. The moderated mediating effect model is proposed. The results provide theoretical guidance for related departments to implement ERs and for enterprises to formulate business strategies. The main conclusions are as follows:

(1) ER and CER. The former can influence the later significantly. Enterprises faced with ERs may be able to improve competitiveness through "first-mover advantage" and "innovation compensation". Thus, the environmental responsibility offers an opportunity for the long-term development in enterprises. It further verifies the Porter Hypothesis.

(2) Mediating effect of altruistic motivation. Altruistic motivation plays a medium role in the relationship between ERs and CER. This offsets the shortages of previous research which emphasized the decisive role of external environment but neglected the influence of personal features.

(3) Moderating effect of green innovation. Green innovation can strengthen the constraints of ER on CER. The higher the level of green innovation, the stronger the willingness of enterprises to undertake environmental responsibility. Attention to value factors such as corporate culture in studying CER is beneficial to improve the smoothness of business strategies.

(4) Moderated mediating effect. The indirect effect of ER on CER through altruistic motivation will be strengthened by green innovation.

\section{Prospect}

This paper has some shortcomings. Firstly, research objects are limited in manufacturing enterprises. Whether heavy-pollution enterprises could represent the current status of Chinese enterprises is doubtful. Future research can expand sample size and involve more industries to improve the universality of conclusions. Secondly, we only choose the most representative personal features as the mediator variable. Whether other personal features have a strong mediating effect still needs further exploration. Therefore, on the one hand, future research should explore the mediating effects of different personal features. On the other hand, attention should be paid to the mediating effects of multiple mediated variables in the relationship between ERs and CER. Thirdly, we only chose enterprise size and property rights as control variables. Future research should consider the effects of other control variables on this model.

Acknowledgments: The authors are grateful to the case company for permitting and supporting this research. This work was financially supported by HRSA, US DHHS (No. H49MC00068), the National Natural Science Foundation of China (No. 71263040, No. 71563030), the Key Projects of Philosophy and Social Science for Universities in Jiangsu (No. 2017ZDIXM119, No. 2017ZDTXM007), the Social Science Foundation of Jiangsu (No. 17GLD013, No. 17DDA007), the Priority Academic Program Development of Jiangsu Higher Education Institutions (PAPD) and the Top-notch Academic Programs Project of Jiangsu Higher Education Institutions (TAPP).

Author Contributions: Benhong Peng and Yu Tu co-designed and wrote the paper, and Guo Wei put forward the valuable suggestions and modified the draft. All authors read and approved the final manuscript.

Conflicts of Interest: The authors declare no conflict of interest.

\section{References}

1. BP Public Limited Company. BP World Energy Statistical Yearbook 2016; BP Public Limited Company: Beijing, China, 2016.

2. Lelieveld, J.; Evans, J.S.; Fnais, M.; Giannadaki, D.; Pozzer, A. The contribution of outdoor air pollution sources to premature mortality on a global scale. Nature 2015, 525, 367-371. [CrossRef] [PubMed]

3. Yang, G.; Wang, Y.; Zeng, Y.; Gao, G.F.; Liang, X.; Zhou, M.; Wan, X.; Yu, S.; Jiang, Y.; Naghavi, M.; et al. Rapid health transition in China, 1990-2010: Findings from the Global Burden of Disease Study 2010. Lancet 2013, 381, 1987-2015. [CrossRef] 
4. Feng, Z.; Chen, W. Environmental regulation, green innovation, and industrial green development: An empirical analysis based on the Spatial Durbin model. Sustainability 2018, 10, 223. [CrossRef]

5. Zhao, X.; Zhang, Y.; Liang, J.; Li, Y.; Jia, R.; Wang, L. The sustainable development of the economic-energy-environment (3E) system under the carbon trading (CT) mechanism: A Chinese case. Sustainability 2018, 10, 98. [CrossRef]

6. Guo, S.; Ding, G.; Zhao, Q.; Jiang, M. Bonus point system for refuse classification and sustainable development: A study in China. Sustainability 2017, 9, 1776. [CrossRef]

7. Agnieszka, M.; Małgorzata, J.K.; Stankiewicz, J. Environmental issues of the corporate social responsibility. Management 2014, 18, 58-70.

8. Rubashkina, Y.; Galeotti, M.; Verdolini, E. Environmental regulation and competitiveness: Empirical evidence on the Porter Hypothesis from European manufacturing sectors. Energy Policy 2015, 83, 288-300. [CrossRef]

9. Ooba, M.; Hayashi, K.; Fujii, M.; Fujita, T.; Machimura, T.; Matsui, T. A long-term assessment of ecological-economic sustainability of woody biomass production in Japan. J. Clean. Prod. 2015, 88, 318-325. [CrossRef]

10. Blackman, A.; Lahiri, B.; Pizer, W.; Planter, M.R.; Pina, C.M. Voluntary environmental regulation in developing countries: Mexico's clean industry program. J. Environ. Econ. Manag. 2010, 60, 182-192. [CrossRef]

11. Testa, F.; Iraldo, F.; Frey, M. The effect of environmental regulation on firms' competitive performance: The case of the building and construction sector in some EU regions. J. Environ. Manag. 2011, 9, 2136-2144. [CrossRef] [PubMed]

12. Brännlund, R.; Lundgren, T. Environmental policy and profitability: Evidence from Swedish industry. Environ. Econ. Policy Stud. 2010, 12, 59-78. [CrossRef]

13. Porter, M.E.; van der Linde, C. Toward a new conception of the environment-Competitiveness relationship. J. Econ. Perspect. 1995, 9, 97-118. [CrossRef]

14. Nie, P.Z.; Huang, L. An empirical study of environmental regulation's different impact on industrial total factor energy productivity. Ind. Econ. Res. 2013, 4, 50-58. (In Chinese)

15. Wu, L.Z.; Kwan, H.K.; Yim, H.K.; Chiu, R.K.; He, X. CEO ethical leadership and corporate social responsibility: A moderated mediation Model. J. Bus. Ethics 2015, 130, 819-831. [CrossRef]

16. Tamborini, R.; Lewis, R.J.; Prabhu, S.; Grizzard, M.; Hahn, L.; Wang, L. Media's influence on the accessibility of altruistic and egoistic motivations. Commun. Res. Rep. 2016, 33, 177-187. [CrossRef]

17. Li, D.; Cao, C.; Zheng, M.; Huang, M.; Ren, S.; Chen, X. The impact of legitimacy pressure and corporate profitability on green innovation: Evidence from China top 100. J. Clean. Prod. 2017, 141, 41-49. [CrossRef]

18. Yang, H. China must continue the momentum of green law. Nature 2014, 509, 535. [CrossRef] [PubMed]

19. Xia, Q.; Li, M.; Wu, H.; Lu, Z. Does the central government's environmental policy work? Evidence from the provincial-level environment efficiency in China. Sustainability 2016, 8, 1241. [CrossRef]

20. Friedman, M. Free to Choose: A Personal Statement; Thomson Learning: Stamford, CT, USA, 1990.

21. Meng, X.H.; Zeng, S.X.; Xie, X.M.; Qi, G.Y. The impact of product market competition on corporate environmental responsibility. Asia Pac. J. Manag. 2016, 33, 267-291. [CrossRef]

22. Lee, M.D.P. Configuration of external influences: The combined effects of institutions and stakeholders on corporate social responsibility strategies. J. Bus. Ethics 2011, 102, 281-298. [CrossRef]

23. Gong, X.; Cortese, C. A socialist market economy with Chinese characteristics: The accounting annual report of China mobile. Account. Forum 2017, 41, 206-220. [CrossRef]

24. Hambrick, D.C.; Mason, P.A. Upper echelons: The organization as a reflection of its top managers. Soc. Sci. Electron. Publ. 1984, 9, 193-206.

25. Haniffa, R.; Hudaib, M. Exploring the ethical identity of Islamic banks via communication in annual reports. J. Bus. Ethics 2007, 76, 97-116. [CrossRef]

26. Trivers, R.L. The evolution of reciprocal altruism. Q. Rev. Biol. 1971, 46, 35-37. [CrossRef]

27. Liu, X.; Zhang, C. Corporate governance, social responsibility information disclosure, and enterprise value in China. J. Clean. Prod. 2016, 142, 1075-1084. [CrossRef]

28. Ghisetti, C.; Rennings, K. Environmental innovations and profitability: How does it pay to be green? An empirical analysis on the German innovation survey. J. Clean. Prod. 2014, 75, 106-117. [CrossRef]

29. McGee, J. Commentary on corporate strategies and environmental regulations: An organizing framework. Strateg. Manag. J. 1998, 19, 377-387. [CrossRef] 
30. Joseph, E. Corporate social responsibility: Delivering the new agenda. Public Policy Res. 2010, 8, 121-123. [CrossRef]

31. Cannella, S.; Framinan, J.M.; Bruccoleri, M.; Barbosa-Póvoa, A.P.; Relvas, S. The effect of inventory record inaccuracy in information exchange supply chains. Eur. J. Oper. Res. 2015, 243, 120-129. [CrossRef]

32. Bergman, M.M.; Bergman, Z.; Berger, L. An empirical exploration, typology, and definition of corporate sustainability. Sustainability 2017, 9, 753. [CrossRef]

33. Campbell, J.L. Why would corporations behave in socially responsible ways? An institutional theory of corporate social responsibility. Acad. Manag. Rev. 2007, 32, 946-967. [CrossRef]

34. He, L.M. Research on oil company's environmental performance information disclosure in separated environmental reports. China Popul. Resour. Environ. 2009, 19, 97-102. (In Chinese)

35. Zeng, S.; Chen, M. Marketing strategy analysis of yogurt under consumption upgrading: A case study of Le Pur. Open J. Soc. Sci. 2017, 5, 195-205. [CrossRef]

36. Palmer, C.; McShane, K.; Sandler, R. Environmental ethics. Annu. Rev. Environ. Resour. 2014, 39, 419-442. [CrossRef]

37. Orlitzky, M.; Schmidt, F.L.; Rynes, S.L. Corporate social and financial performance: A meta-analysis. Organ. Stud. 2008, 24, 403-441. [CrossRef]

38. Graafland, J. Motives for corporate social responsibility. Economist 2012, 160, 377-396. [CrossRef]

39. Giroud, X.; Mueller, H.M. Corporate governance, product market competition, and equity prices. J. Financ. 2011, 66, 563-600. [CrossRef]

40. Osman, L.H.B. How structure influence relational capital: The impact of network communication in centralized structure. Aust. J. Ophthalmol. 2015, 7, 114-125. [CrossRef]

41. Pentland, B.T.; Hærem, T. Organizational routines as patterns of action: Implications for organizational behavior. Organ. Stud. 2015, 2, 465-487. [CrossRef]

42. Flamholtz, E.G.; Randle, Y. Corporate culture, business models, competitive advantage, strategic assets and the bottom line. J. Hum. Resour. Cost. Account. 2012, 16, 76-94. [CrossRef]

43. Chen, Y.S.; Lai, S.B.; Wen, C.T. The influence of green innovation performance on corporate advantage in Taiwan. J. Bus. Ethics 2006, 67, 331-339. [CrossRef]

44. Marx, A. Ecological modernization, environmental policy and employment: Can environmental protection and employment be reconciled? Innov. Eur. J. Soc. Sci. Res. 2000, 13, 311-325. [CrossRef]

45. Wang, J.M.; Chen, H.X.; Yuan, Y. Mediating role of green innovation strategy of firm enterprises in Jiangsu. China Popul. Resour. Environ. 2010, 20, 111-117. (In Chinese)

46. Nath, P.; Ramanathan, R.; Black, A.; Lamond, D.; Muyldermans, L. Impact of environmental regulations on innovation and performance in the UK industrial sector. Manag. Decis. 2010, 48, 1493-1513.

47. Edwards, J.R.; Lambert, L.S. Methods for integrating moderation and mediation: A general analytical framework using moderated path analysis. Psychol. Methods 2007, 12, 1-22. [CrossRef] [PubMed]

48. Kshetri, N. Institutional factors affecting offshore business process and information technology outsourcing. J. Int. Manag. 2007, 13, 38-56. [CrossRef]

49. Feng, Z. Conformity or compliance: Corporations' choice of social responsibility under institutional pressure. Financ. Econ. 2014, 4, 82-90.

50. Tian, Q.; Liu, Y.; Fan, J. The effects of external stakeholder pressure and ethical leadership on corporate social responsibility in China. J. Manag. Organ. 2015, 21, 388-410. [CrossRef]

51. Wahba, H. Does the market value corporate environmental responsibility? An empirical examination. Eco-Manag. Audit. 2008, 15, 89-99. [CrossRef]

52. Testa, M.; D'Amato, A. Corporate environmental responsibility and financial performance: Does bidirectional causality work? Empirical evidence from the manufacturing industry. Soc. Responsib. J. 2017, 13, 221-234. [CrossRef]

53. Schwartz, S.H.; Boehnke, K. Evaluating the structure of human values with confirmatory factor analysis. J. Res. Personal. 2004, 38, 230-255. [CrossRef]

54. Chang, C.H. The influence of corporate environmental ethics on competitive advantage: The mediation role of green innovation. J. Bus. Ethics 2011, 104, 361-370. [CrossRef]

55. Judge, W.Q.; Douglas, T.J. Performance implications of incorporating natural environmental issues into the strategic planning process: An empirical assessment. J. Manag. Stud. 1998, 35, 241-262. [CrossRef] 
56. Baron, R.M.; Kenny, D.A. The moderator-mediator variable distinction in social psychological research: Conceptual, strategic, and statistical considerations. J. Personal. Soc. Psychol. 1986, 51, 1173-1182. [CrossRef]

57. Clemens, B.; Bakstran, L. A framework of theoretical lenses and strategic purposes to describe relationships among firm environmental strategy, financial performance, and environmental performance. Manag. Res. Rev. 2016, 33, 393-405. [CrossRef]

58. Dibrell, C.; Craig, J.B.; Hansen, E.N. How managerial attitudes toward the natural environment affect market orientation and innovation. J. Bus. Res. 2011, 64, 401-407. [CrossRef]

59. Lanoie, P.; Patry, M.; Lajeunesse, R. Environmental regulation and productivity: Testing the Porter Hypothesis. J. Product. Anal. 2008, 30, 121-128. [CrossRef]

60. Kahneman, D.; Knetsch, J.L.; Thaler, R. Fairness as a constraint on profit seeking: Entitlements in the market. Am. Econ. Rev. 1986, 76, 728-741.

61. Mitchell, A.; Madill, J.; Chreim, S. Social enterprise dualities: Implications for social marketing. J. Soc. Mark. 2016, 6, 169-192. [CrossRef]

62. Mckague, K.; Zietsma, C.; Oliver, C. Building the social structure of a market. Organ. Stud. 2015, 36, 1063-1093. [CrossRef]

63. Tu, Y.; Peng, B.H. On the Relation of Dual Social Capital, Dual Learning and Open Services Innovation Performance in the Platform Enterprise. Sci. Technol. Process Policy 2017, 34, 83-90.

64. Wu, T.; Wu, Y.C.J.; Chen, Y.J.; Goh, M. Aligning supply chain strategy with corporate environmental strategy: A contingency approach. Int. J. Prod. Econ. 2014, 147, 220-229. [CrossRef]

65. Roxas, B.; Coetzer, A. Institutional environment, managerial attitudes and environmental sustainability orientation of small firms. J. Bus. Ethics 2012, 111, 461-476. [CrossRef]

66. Bezdek, R.H.; Wendling, R.M.; Diperna, P. Environmental protection, the economy, and jobs: National and regional analyses. J. Environ. Manag. 2008, 86, 63-79. [CrossRef] [PubMed]

(C) 2018 by the authors. Licensee MDPI, Basel, Switzerland. This article is an open access article distributed under the terms and conditions of the Creative Commons Attribution (CC BY) license (http:/ / creativecommons.org/licenses/by/4.0/). 